\title{
Clinical Outcomes of Off-Label Dosing of Direct Oral Anticoagulant Therapy Among Japanese Patients With Atrial Fibrillation Identified From the SAKURA AF Registry
}

\author{
Nobuhiro Murata, MD; Yasuo Okumura, MD; Katsuaki Yokoyama, MD; \\ Naoya Matsumoto, MD; Eizo Tachibana, MD; Keiichiro Kuronuma, MD; Koji Oiwa, MD; \\ Michiaki Matsumoto, MD; Toshiaki Kojima, MD; Shoji Hanada, MD; \\ Kazumiki Nomoto, MD; Ken Arima, MD; Fumiyuki Takahashi, MD; Tomobumi Kotani, MD; \\ Yukitoshi Ikeya, MD; Seiji Fukushima, MD; Satoru Itoh, MD; Kunio Kondo, MD; \\ Masaaki Chiku, MD; Yasumi Ohno, MD; Motoyuki Onikura, MD; \\ Atsushi Hirayama, MD for the SAKURA AF Registry Investigators
}

Background: Off-label dosing of direct oral anticoagulants (DOACs) is encountered clinically among patients with atrial fibrillation (AF), although data on the clinical outcomes of over- and under-dosing are lacking in Japan.

\begin{abstract}
Methods and Results: We examined the clinical outcomes of off-label DOAC dosing using the SAKURA AF Registry, a prospective multicenter registry in Japan. Among 3,237 enrollees, 1,676 under any of the 4 DOAC regimens were followed up for a median of 39.3 months: 746 (45.0\%), appropriate standard-dose; 477 (28.7\%), appropriate low-dose; 66 (4.0\%), over-dose; and 369 (22.2\%) under-dose. Compared with the standard-dose group, patients in the under- and over-dose groups were significantly older and had a higher stroke risk. After multivariate adjustment, stroke/systemic embolism (SE) and death events were equivalent between the standard- and under-dose groups, but major bleeding events tended to be lower in the under-dose group (hazard ratio [HR] 0.474 , $\mathrm{P}=0.0739$ ). Composite events (stroke/SE, major bleeding, or death) were higher in the over-dose than in the standard-dose group (HR 2.714, $\mathrm{P}=0.0081$ ).
\end{abstract}

Conclusions: Clinical outcomes were not worse for under-dose than for standard-dose users among patients with different backgrounds. Over-dose users, however, were at higher risk for all clinical events and required careful follow-up. Further studies are needed to clarify the safety and effectiveness of off-label DOAC dosing in Japan.

Key Words: Atrial fibrillation; Direct oral anticoagulants; Off-label dose therapy

A trial fibrillation (AF) is the most common arrhythmia in elderly individuals, currently affecting approximately $0.6 \%$ of the Japanese population, and the prevalence of AF is expected to continue to rise in Japan, affecting an estimated 10 million people by $2030 .{ }^{1} \mathrm{AF}$ is a strong risk factor for stroke and death. Randomized clinical trials (RCTs) have shown the benefit of direct oral anticoagulant (DOAC) therapy in reducing the risk of stroke and

\section{Editorial p 707}

bleeding complications among patients with AF, compared with use of vitamin $\mathrm{K}$ antagonists. ${ }^{2-5}$ Review of real-world registries in Japan has indicated the incidence rate of stroke with DOAC therapy to be similar to that with warfarin but with a lower risk for major bleeding events for DOACs

Received September 6, 2018; revised manuscript received December 19, 2018; accepted December 25, 2018; J-STAGE Advance Publication released online February 5, 2019 Time for primary review: 26 days

Division of Cardiology, Nihon University Itabashi Hospital, Tokyo (N. Murata, Y. Okumura, A.H.); Department of Cardiology, Nihon University Hospital, Tokyo (K.Y., N. Matsumoto); Kawaguchi Municipal Medical Center, Saitama (E.T., K. Kuronuma); Yokohama Chuo Hospital, Kanagawa (K.O., M.M.); Sekishindo Hospital, Saitama (T. Kojima); TMG Asaka Medical Center, Saitama (S.H.); Tokyo Rinkai Hospital, Tokyo (K.N.); Kasukabe Medical Center, Saitama (K.A.); Yasuda Hospital, Tokyo (F.T.); Makita General Hospital, Tokyo (T. Kotani); Itabashi Medical Association Hospital, Tokyo (Y.I.); Ukima Central Hospital, Tokyo (S.F.); Itou Cardiovascular Clinic, Saitama (S.I.); Kondo Clinic, Tokyo (K. Kondo); Keiai Clinic, Tokyo (M.C.); Ohno Medical Clinic, Tokyo (Y. Ohno); and Onikura Clinic, Chiba (M.O.), Japan

Mailing address: Yasuo Okumura, MD, Division of Cardiology, Department of Medicine, Nihon University School of Medicine, Ohyaguchi-kamicho, Itabashi-ku, Tokyo 173-8610, Japan. E-mail: okumura.yasuo@nihon-u.ac.jp

ISSN-1346-9843 All rights are reserved to the Japanese Circulation Society. For permissions, please e-mail: cj@j-circ.or.jp 
than for warfarin. ${ }^{6}$ As such, in clinical settings in Japan, physicians do inappropriately reduce the dose of any DOAC, despite knowledge of the criteria for a standarddose regimen, in an attempt to lower the risk of bleeding. Off-label reduced doses are most commonly prescribed for patients who are older, as well as those with low body weight and low renal function. ${ }^{6,7}$ These individuals are also at risk for inappropriate over-dosing of DOAC if the standard dose is not appropriately reduced to consider the effects of older age, low body weight and low renal function.

Both off-label low and standard doses (namely underand over-dosing, respectively) are clinically problematic as both could, theoretically, increase the risk for stroke and major bleeding events. As such, clinical data regarding the outcomes of under- and over-dosing among DOAC users in Japan are needed. To address this issue, we established a multicenter registry, the SAKURA AF Registry (UMIN Clinical Trials Registry: UMIN000014420) (Supplementary Appendix), to support prospective observational research into the current status of anticoagulation therapy in Japan. In a previous study, we reported on our identification of over- and under-dosing among DOAC users in the registry. ${ }^{6}$ Our aim in this study was to explore the clinical implications of off-label dosing of DOAC therapy among Japanese patients with AF.

\section{Methods}

\section{Study Population}

The study design, data collection processes and baseline characteristics of the study population have been reported.8,9 Patient eligibility for enrollment into the registry was as follows: a diagnosis of non-valvular AF, based on 12-lead ECG, 24-hour Holter ECG recording or event-activated ECG recording; age $\geq 20$ years; and treatment (either just initiated or already in place) using any anticoagulant drug for stroke prophylaxis. Recruitment began in September 2013 and ended in December 2015. The registry includes 1,578 patients who were treated with warfarin at the time of enrollment, and 1,690 treated with any of the 4 available DOACs. A total of 3,268 patients were enrolled into the registry by 63 institutions (2 cardiovascular centers, 20 affiliated hospitals or community hospitals and 41 private clinics) in the Tokyo area. Analysis of the Registry data were approved by our institutional review board (IRB) and the individual hospital IRBs. All enrollees provided written informed consent for participation in the Registry.

\section{Data Collection and Outcomes}

A web-based registration system was created for the SAKURA AF Registry and is currently being used to collect relevant patient clinical data (comorbidities, medication use and laboratory test results) and to obtain follow-up information, including: PT-INR of warfarin users; creatinine clearance $(\mathrm{CrCl})$ rate; and hemoglobin (Hb) concentration. These follow-up data are collected through a central registry office, twice a year (in March and September), for up to 4 years after enrollment. The time in therapeutic range was calculated using the Rosendaal method. ${ }^{10}$ The primary endpoint of our study was an event of stroke (ischemic stroke, hemorrhagic stroke, or transient ischemic attack [TIA]) or systemic embolism (SE). Cardiovascular death or death from any cause was also recorded. Major bleeding was defined as a reduction in the $\mathrm{Hb}$ level of at least $2 \mathrm{~g} / \mathrm{dL}$, transfusion of at least 2 units of blood or symptomatic bleeding in a critical area or organ, and was specified as the endpoint of safety.,211 The net clinical events (composite of stroke or SE, major bleeding, or death from any cause) was also taken as a study endpoint.

\section{Definitions}

For the administration of DOACs, "appropriate standarddose" and "appropriate low-dose" were defined as administration according to a standard or low-dose regimen, respectively. The following low-dose regimens were considered to be appropriate: dabigatran, $110 \mathrm{mg}$ (b.i.d.), for patients with a $\mathrm{CrCl}$ of $30-50 \mathrm{~mL} / \mathrm{min}$, age $\geq 70$ years and a prior history of bleeding;,211 rivaroxaban, $10 \mathrm{mg}$ (o.d.), for patients with a $\mathrm{CrCl}$ of $15-50 \mathrm{~mL} / \mathrm{min} ; \mathbf{3 , 1 2}$ apixaban, $2.5 \mathrm{mg}$ (b.i.d.), for patients with any 2 of the following characteristics: $\geq 80$ years, body weight $<60 \mathrm{~kg}$ and serum $\mathrm{Cr}$ level $\geq 1.5 \mathrm{mg} / \mathrm{dL} ; \mathbf{4 , 1 3}$ and edoxaban, $30 \mathrm{mg}$ (o.d.), for patients with a $\mathrm{CrCl}$ of $15-50 \mathrm{~mL} / \mathrm{min}$ or body weight is $<60 \mathrm{~kg}^{5}$ Under-dosing (off-label low-dose) therapy was defined as administration of a low-dose of DOAC despite the standard dosage criteria being met. Over-dosing (off-label standarddose) therapy was defined as administration of a standarddose of DOAC despite the low-dose regimen criteria being met. Dabigatran was considered to be contraindicated for patients with a $\mathrm{CrCl}<30 \mathrm{~mL} / \mathrm{min},{ }^{2,11}$ with the other DOACs contraindicated for patients with a $\mathrm{CrCl}<15 \mathrm{~mL} / \mathrm{min}^{3-5,11-13}$ Of note, although under-dosing of dabigatran (to $110 \mathrm{mg}$, b.i.d.) was selected based on the rule previously described (namely, $\mathrm{CrCl} 30-50 \mathrm{~mL} / \mathrm{min}$, age $\geq 70$ years; prior bleeding), rather than based on a standard dose, almost all physicians followed the defined rule for dabigatran under-dosing.

\section{Statistical Analysis}

Continuous variables are reported as the mean \pm standard deviation (SD), with categorical variables reported as the percentage and number of patients. Differences in continuous variables between the 4 DOAC groups (over-dose vs. appropriate standard-dose vs. appropriate low-dose vs. under-dose) were evaluated using a one-way analysis of variance (ANOVA), with between-group differences in categorical variables evaluated using a chi-squared test. Kaplan-Meier curves of the cumulative incidence of stroke or SE, major bleeding, all-cause death, and composite net clinical events were constructed and compared between the 4 DOAC dose groups using a log-rank test. Considering the potential effects of antiplatelet use on clinical outcomes in the off-label under-dose group, we compared clinical outcomes between the off-label under-dose vs. standarddose groups using the Fisher exact test. The results of Cox proportional hazards modeling for clinical outcomes in the under-dose, appropriate low-dose and over-dose groups vs. the appropriate standard-dose groups are expressed as hazard ratios (HRs) and 95\% confidence intervals (CIs). The models were adjusted by propensity score, calculated using sex, age, body weight, persistent $\mathrm{AF}$, new use of DOAC, hypertension, diabetes mellitus, heart failure, history of stroke/TIA, vascular disease, history of AF ablation, $\mathrm{CrCl}$, and antiplatelet drug use. All statistical analyses were performed using SPSS Statistics 24 (IBM Corp., Armonk, NY, USA), with a P-value $<0.05$ considered significant. 


\begin{tabular}{|c|c|c|c|c|c|c|}
\hline & \multicolumn{6}{|c|}{ DOACs } \\
\hline & $\begin{array}{l}\text { Overall } \\
(n=1,658)\end{array}$ & $\begin{array}{l}\text { Over-dose } \\
\quad(n=66)\end{array}$ & $\begin{array}{c}\text { Appropriate } \\
\text { standard-dose }(n=746)\end{array}$ & $\begin{array}{c}\text { Appropriate } \\
\text { low-dose }(n=477)\end{array}$ & $\begin{array}{l}\text { Under-dose } \\
(n=369)\end{array}$ & P value* \\
\hline Age (years) & $71.7 \pm 9.5$ & $76.0 \pm 5.0$ & $66.9 \pm 9.0$ & $79.2 \pm 6.0$ & $71.2 \pm 8.2$ & $<0.001$ \\
\hline Female & $473(28.5)$ & $20(30.3)$ & $161(21.6)$ & $185(38.8)$ & $107(29.0)$ & $<0.001$ \\
\hline Height $(\mathrm{cm})$ & $162.1 \pm 9.6$ & $159.3 \pm 7.8$ & $165.2 \pm 8.8$ & $157.7 \pm 9.4$ & $162.3 \pm 9.1$ & $<0.001$ \\
\hline Weight (kg) & $63.8 \pm 13.4$ & $58.6 \pm 9.5$ & $68.6 \pm 13.3$ & $56.4 \pm 11.0$ & $64.7 \pm 12.4$ & $<0.001$ \\
\hline $\mathrm{BMI}\left(\mathrm{kg} / \mathrm{m}^{2}\right)$ & $24.1 \pm 3.9$ & $23.0 \pm 2.5$ & $25.0 \pm 4.0$ & $22.6 \pm 3.3$ & $24.5 \pm 3.8$ & 0.209 \\
\hline High alcohol use ( $\geq 160 \mathrm{~g} /$ day $)$ & $48(2.9)$ & $0(0)$ & $39(5.2)$ & $1(0.2)$ & $8(2.2)$ & $<0.001$ \\
\hline \multicolumn{7}{|l|}{ AF type } \\
\hline Paroxysmal & $700(42.2)$ & $27(40.9)$ & $330(44.2)$ & $176(36.9)$ & $167(45.3)$ & $<0.001$ \\
\hline Persistent & $346(20.9)$ & $11(16.7)$ & $161(21.6)$ & $97(20.3)$ & 77 (20.9) & 0.491 \\
\hline LS-AF & $599(36.1)$ & $27(40.9)$ & $248(33.2)$ & $200(41.9)$ & $124(33.6)$ & $<0.001$ \\
\hline \multicolumn{7}{|l|}{ Previous history } \\
\hline Hypertension & $1,151(69.4)$ & $46(69.7)$ & $508(68.1)$ & $334(70.0)$ & 263 (71.3) & 0.730 \\
\hline Diabetes & $358(21.6)$ & $14(21.2)$ & $166(22.3)$ & $96(20.1)$ & $82(22.2)$ & 0.828 \\
\hline Heart failure & $316(19.1)$ & $5(7.6)$ & $122(16.4)$ & $123(25.8)$ & $66(17.9)$ & $<0.001$ \\
\hline Vascular disease & $194(11.7)$ & $7(10.6)$ & $74(9.9)$ & $60(12.6)$ & $53(14.4)$ & 0.154 \\
\hline Stroke/TIA & $175(10.1)$ & $10(15.2)$ & $71(9.5)$ & $66(13.8)$ & $28(7.6)$ & 0.011 \\
\hline Major bleeding & $16(0.9)$ & $1(1.5)$ & $4(0.5)$ & $6(1.3)$ & $5(1.4)$ & 0.447 \\
\hline AF ablation & $154(9.3)$ & $4(6.1)$ & $92(12.3)$ & $18(3.8)$ & $40(10.8)$ & $<0.001$ \\
\hline Antiplatelet use & $211(12.7)$ & $11(16.7)$ & $85(11.4)$ & $63(13.2)$ & $52(14.1)$ & 0.418 \\
\hline NSAIDs & $33(2.0)$ & $2(3.0)$ & $13(1.7)$ & $12(2.5)$ & $6(1.6)$ & 0.676 \\
\hline \multicolumn{7}{|l|}{ DOAC type } \\
\hline Dabigatran & $449(27.1)$ & $35(53.0)$ & $88(11.8)$ & $234(49.1)$ & $92(24.9)$ & $<0.001$ \\
\hline Rivaroxaban & $754(45.5)$ & $25(37.9)$ & $406(54.4)$ & $138(28.9)$ & $185(50.1)$ & $<0.001$ \\
\hline Apixaban & $424(25.6)$ & $4(6.1)$ & 246 (33.0) & $92(19.3)$ & $82(22.2)$ & $<0.001$ \\
\hline Edoxaban & $31(1.9)$ & $2(3.0)$ & $6(0.8)$ & $13(2.7)$ & $10(2.7)$ & $<0.001$ \\
\hline $\mathrm{CHADS}_{2}$ score & $1.72 \pm 1.14$ & $1.83 \pm 1.09$ & $1.45 \pm 1.06$ & $2.19 \pm 1.16$ & $1.64 \pm 1.09$ & $<0.0001$ \\
\hline $\mathrm{CHA}_{2} \mathrm{DS}_{2}-\mathrm{VASc}$ score & $2.92 \pm 1.46$ & $3.24 \pm 1.28$ & $2.42 \pm 1.39$ & $3.69 \pm 1.31$ & $2.88 \pm 1.39$ & $<0.0001$ \\
\hline HAS-BLED score & $1.28 \pm 0.78$ & $1.52 \pm 0.70$ & $1.16 \pm 0.85$ & $1.46 \pm 0.64$ & $1.25 \pm 0.78$ & $<0.0001$ \\
\hline $\mathrm{CrCl}(\mathrm{mL} / \mathrm{min})$ & $70.5 \pm 27.2$ & $58.8 \pm 18.6$ & $84.1 \pm 27.5$ & $51.2 \pm 17.8$ & $70.1 \pm 21.2$ & $<0.0001$ \\
\hline
\end{tabular}

Values are shown as mean \pm SD or $n(\%) .12$ patients (not reported), 6 patients (contraindication) DOAC dose users were excluded. AF, atrial fibrillation; BMI, body mass index; $\mathrm{CHADS}_{2}$, congestive heart failure, hypertension, age $\geq 75$ years, diabetes and stroke; $\mathrm{CHA}_{2} \mathrm{DS} 2-\mathrm{VASc}$ congestive heart failure, hypertension, age $\geq 75$ years, diabetes, stroke, vascular disease, age 65-74 years and sex category; $\mathrm{CrCl}$, creatinine clearance; DOAC, direct oral anticoagulant; HAS-BLED, uncontrolled hypertension (baseline systolic blood pressure $>160 \mathrm{mmHg}$ ), abnormal renal function (serum creatinine $\geq 2.26 \mathrm{mg} / \mathrm{dL}$ )/liver function (chronic hepatic disease [e.g., cirrhosis] or aspartate aminotransferase and/or alanine aminotransferase $>3 \times n$ ormal range), stroke, prior major bleeding, elderly (age $\geq 65$ years), drugs (antiplatelet drugs or nonsteroidal anti-inflammatory drugs)/high alcohol use, Labile INR (over-dosing shown by baseline PT-INR in warfarin users); LS-AF; long-standing persistent AF (>1 year); NA, not applicable; TIA, transient ischemic attack. ${ }^{*}$ Comparison between 4 dose groups of DOAC users by ANOVA or chi-squared test, as appropriate.

\section{Results}

Baseline Characteristics

Of the 3,268 patients enrolled in the SAKURA AF Registry, 31 were lost to follow-up. Follow-up data at the 1- and 2-year endpoints after enrollment into the Registry for $3,157(97.5 \%)$ and, $2,952(91.2 \%)$, respectively, was available for the 3,237 remaining enrollees. Among these 3,237 patients, $48.8 \%(n=1,561)$ were warfarin users and $51.2 \%$ $(n=1,676)$ DOAC users. Of these 3,237 patients, the use of DOACs was contraindicated in 6 patients and the dose was not reported in another 12 patients. The data from these patients were excluded, with our analysis being ultimately based on the data of 1,658 patients. DOAC were used at the appropriate standard-dose in $746(45.0 \%)$ of the patients and at an appropriate low-dose in 477 (28.7\%), with $66(4.0 \%)$ being treated with an over-dose and 369
$(22.2 \%)$ with an under-dose. Baseline characteristics of the study population are summarized in Table $\mathbf{1}$.

Compared with the mean age of the standard-dose group (66.9 \pm 9.0 years), patients were older in the appropriate low-dose (79.2 \pm 6.0 years), under-dose ( $71.2 \pm 8.2$ years) and over-dose ( $76.0 \pm 5.0$ years) groups $(\mathrm{P}<0.001)$. In addition, the proportion of women was higher in the appropriately low $(38.8 \%)$, under-dose $(29.0 \%)$ and over-dose $(30.3 \%)$ groups than in the standard-dose $(21.6 \%)$ group $(\mathrm{P}<0.001)$. With regard to clinical features, compared with the standard-dose group, body weight $(\mathrm{P}<0.001)$ and $\mathrm{CrCl}$ $(\mathrm{P}<0.001)$ were lower in the appropriately low, under-dose and over-dose group, and the $\mathrm{CHADS}_{2}$ and $\mathrm{CHA}_{2} \mathrm{DS}_{2}$-Vasc scores were higher $(\mathrm{P}<0.001)$. The consumption of alcohol was lower in each of these 3 dosing groups, compared with the standard-dose group $(\mathrm{P}<0.001)$. There were no differences in other clinical features, including antiplatelet use, 


\begin{tabular}{|c|c|c|c|c|c|c|c|c|c|c|c|}
\hline & $\underset{(n=1}{O v e}$ & $\begin{array}{l}\text { erall } \\
1,658)\end{array}$ & $\begin{array}{r}\text { Over } \\
(n=\end{array}$ & $\begin{array}{l}\text { r-dose } \\
=66)\end{array}$ & $\begin{array}{l}\text { Approprie } \\
\text { dose }\end{array}$ & $\begin{array}{l}\text { ate standard- } \\
(n=746)\end{array}$ & $\begin{array}{c}\text { Approp } \\
\text { dose }\end{array}$ & $\begin{array}{l}\text { riate low- } \\
(n=477)\end{array}$ & $\begin{array}{r}\text { Unde } \\
(n=\end{array}$ & $\begin{array}{l}\text { er-dose } \\
=369 \text { ) }\end{array}$ & \\
\hline & Total & $\begin{array}{c}\text { Event rate } \\
\text { per } 100 \\
\text { patient- } \\
\text { years }\end{array}$ & Total & $\begin{array}{c}\text { Event rate } \\
\text { per } 100 \\
\text { patient- } \\
\text { years }\end{array}$ & Total & $\begin{array}{c}\text { Event rate } \\
\text { per } 100 \\
\text { patient- } \\
\text { years }\end{array}$ & Total & $\begin{array}{c}\text { Event rate } \\
\text { per } 100 \\
\text { patient- } \\
\text { years }\end{array}$ & Total & $\begin{array}{c}\text { Event rate } \\
\text { per } 100 \\
\text { patient- } \\
\text { years }\end{array}$ & P value \\
\hline Thromboembolism & $69(4.1)$ & 1.47 & $6(0.9)$ & 3.53 & $25(3.3)$ & 1.17 & $27(5.6)$ & 2.07 & $11(2.9)$ & 1.02 & 0.010 \\
\hline Ischemic stroke & $61(3.7)$ & 1.30 & $5(7.6)$ & 2.92 & $21(2.8)$ & 0.98 & $24(5.0)$ & 1.83 & $11(3.0)$ & 1.02 & 0.029 \\
\hline TIA & $5(0.3)$ & 0.11 & $2(3)$ & 1.17 & $2(0.3)$ & 0.09 & $1(0.2)$ & 0.08 & $0(0)$ & 0 & 0.001 \\
\hline SE & $2(0.1)$ & 0.04 & $0(0)$ & 0 & $0(0)$ & 0 & $2(0.4)$ & 0.15 & $0(0)$ & 0 & 0.126 \\
\hline $\begin{array}{l}\text { Hemorrhagic } \\
\text { stroke }\end{array}$ & $2(0.1)$ & 0.04 & $0(0)$ & 0 & $2(0.3)$ & 0.09 & $0(0)$ & 0 & $0(0)$ & 0 & 0.501 \\
\hline All-cause death & $89(5.4)$ & 1.87 & $7(11)$ & 4.01 & $14(1.9)$ & 0.64 & $54(11.3)$ & 4.07 & $14(3.8)$ & 1.28 & $<0.001$ \\
\hline Cardiovascular & $20(1.2)$ & 0.42 & $3(4.5)$ & 1.71 & $1(0.1)$ & 0.05 & $14(2.9)$ & 1.06 & $2(0.5)$ & 0.18 & $<0.001$ \\
\hline $\begin{array}{l}\text { Non- } \\
\text { cardiovascular }\end{array}$ & $69(4.2)$ & 1.45 & $4(6.1)$ & 2.29 & $13(1.7)$ & 0.60 & $40(8.4)$ & 3.01 & $12(3.3)$ & 1.10 & $<0.001$ \\
\hline Major bleeding & $57(3.4)$ & 1.21 & $5(7.6)$ & 3.00 & $26(3.5)$ & 1.21 & $19(4.0)$ & 1.45 & $7(1.9)$ & 0.64 & 0.042 \\
\hline Intracranial & 22 (1.3) & 0.46 & $1(1.5)$ & 0.57 & $10(1.3)$ & 0.46 & 7 (1.5) & 0.53 & $4(1.1)$ & 0.37 & 0.942 \\
\hline $\begin{array}{l}\text { Composite net } \\
\text { clinical events }\end{array}$ & $174(10.5)$ & 3.74 & $17(25.8)$ & 10.49 & $49(6.6)$ & 2.31 & $80(16.8)$ & 6.18 & $28(7.6)$ & 2.61 & $<0.001$ \\
\hline
\end{tabular}

Values are shown as $\mathrm{n}(\%)$. Composite net clinical events=composite of stroke or $\mathrm{SE}$, major bleeding, or death from any cause. ${ }^{*}$ per chi-square test, as appropriate. 12 not reported, 6 contraindication DOAC dosages were excluded. SE, systemic embolism. Other abbreviations as in Table 1.

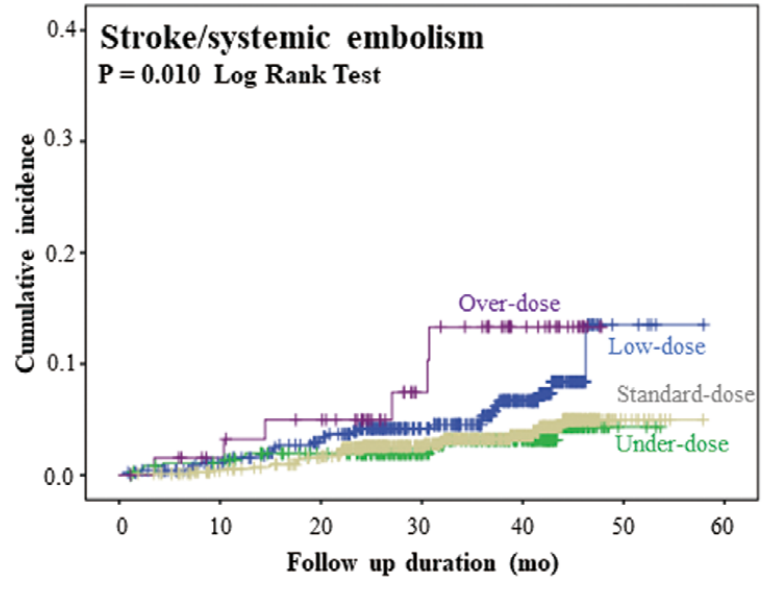

Patients at risk

$\begin{array}{lcccccc}\text { Months } & 0 & 10 & 20 & 30 & 40 & 50 \\ \text { Over-dose } & 66 & 59 & 55 & 34 & 18 & 0 \\ \text { Low-dose } & 477 & 444 & 408 & 300 & 175 & 4 \\ \text { Standard-dose } & 746 & 721 & 693 & 492 & 282 & 13 \\ \text { Under-dose } & 369 & 359 & 339 & 261 & 154 & 2\end{array}$

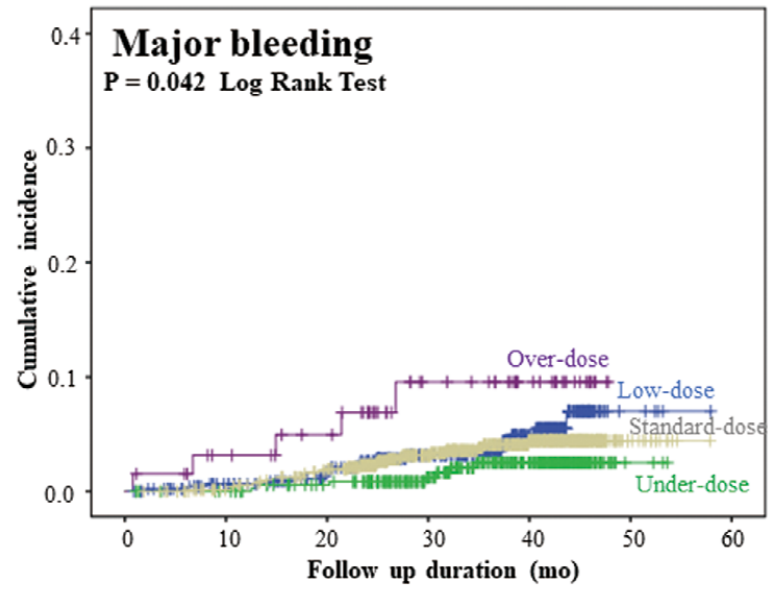

Patients at risk

$\begin{array}{lcccccc}\text { Months } & 0 & 10 & 20 & 30 & 40 & 50 \\ \text { Over-dose } & 66 & 58 & 52 & 32 & 19 & 0 \\ \text { Low-dose } & 477 & 445 & 412 & 301 & 175 & 4 \\ \text { Standard-dose } & 746 & 723 & 690 & 492 & 281 & 13 \\ \text { Under-dose } & 369 & 362 & 343 & 262 & 155 & 2\end{array}$

Figure 1. Kaplan-Meier curves for stroke or systemic embolism and major bleeding among patients prescribed direct oral anticoagulant at an over-dose, appropriate standard-dose, appropriate low-dose, and under-dose. 

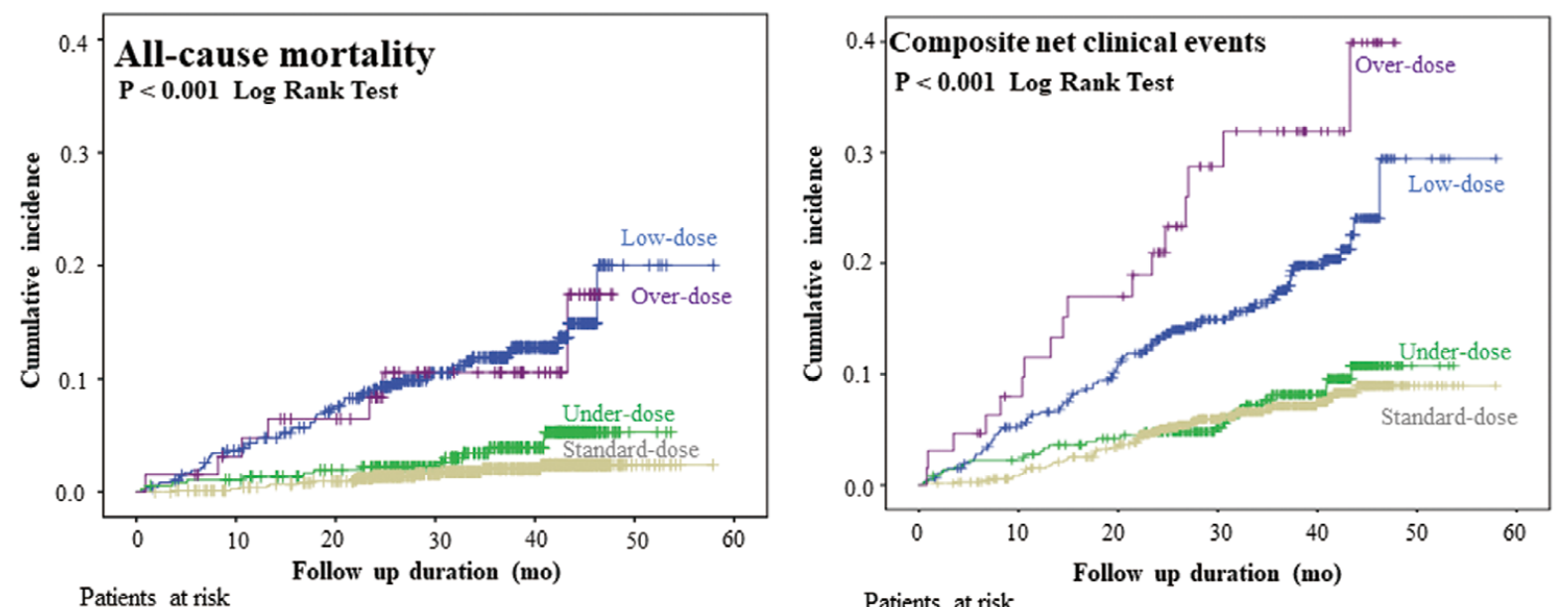

$\begin{array}{lcccccc}\text { Months } & 0 & 10 & 20 & 30 & 40 & 50 \\ \text { Over-dose } & 66 & 60 & 55 & 35 & 21 & 0 \\ \text { Low-dose } & 477 & 449 & 417 & 307 & 179 & 4 \\ \text { Standard-dose } & 746 & 724 & 702 & 506 & 293 & 12 \\ \text { Under-dose } & 369 & 361 & 343 & 263 & 157 & 2\end{array}$

$\begin{array}{lcccccc}\text { Patients at risk } & & & & & & \\ \text { Months } & 0 & 10 & 20 & 30 & 40 & 50 \\ \text { Over-dose } & 66 & 57 & 52 & 31 & 17 & 0 \\ \text { Low-dose } & 477 & 442 & 404 & 295 & 173 & 4 \\ \text { Standard-dose } & 746 & 720 & 683 & 483 & 275 & 13 \\ \text { Under-dose } & 369 & 358 & 339 & 257 & 153 & 2\end{array}$

Figure 2. Kaplan-Meier curves for all-cause mortality and net clinical events among patients prescribed direct oral anticoagulant at an over-dose, appropriate standard-dose, appropriate low-dose, and under-dose. Net clinical events include stroke or systemic embolism, major bleeding, all-cause mortality.

among the 4 groups.

\section{Clinical Outcomes}

At a median follow-up of 39.3 months (range, 28.5-43.6 months), after enrollment, a thromboembolic event was identified in 69 patients $(4.2 \%)$ and a major bleeding event in $57(3.4 \%) ; 89(5.4 \%)$ patients died (Table 2). The Kaplan-Meier curves for stroke or SE, major bleeding, all-cause death, and for the net clinical events (defined as the composite of stroke or SE, major bleeding or death from any cause) are shown in Figures $\mathbf{1}$ and $\mathbf{2}$ for the 4 different DOAC dose groups. The incidence of a stroke/SE event was higher in the over-dose and appropriate low-dose groups, compared with either the appropriate standard-dose or under-dose groups $(\mathrm{P}=0.010$ log-rank test $)$. The incidence of a major bleeding event was higher in the over-dose group than either the appropriate standard- or low-dose groups, but lower in the under-dose group $(\mathrm{P}=0.042$, log-rank test). The incidence of all-cause death and composite net clinical events was higher in the over-dose and appropriate low-dose groups than in the appropriate standard- and under-dose groups $(\mathrm{P}<0.001$, log-rank test for both). In the off-label under-dose group, we did not identify differences between patients using or not using concomitant antiplatelet drugs, with regard to the incidence of stroke/SE (1.9\% [1/52] vs. 3.2\% [10/317], $\mathrm{P}>0.999)$, major bleeding $(3.9 \%[2 / 52]$ vs. $1.6 \%[5 / 317], \mathrm{P}=0.2576)$, death $(3.9 \%$ [2/52] vs. $3.8 \%$ [12/317], $\mathrm{P}>0.999)$, or net clinical events (7.7\% [4/51] vs. 7.6\% [24/317], P>0.999). Results of the Cox regression analysis of the relative risk of stroke/SE, a major bleeding event, all-cause death, and the composite net clinical events for the appropriate low-, under- and over-dose groups, compared with the appropriate standarddose group, are summarized in Table 3. The principal findings, after adjustment by propensity score, were as follows. First, there was no difference in the risk of stroke/SE between the appropriate standard-dose group and each of the other 3 DOAC dose groups. Second, the risk of major bleeding was equivalent for the appropriate standard-dose and the under- and appropriate low-dose groups, but tended to be lower in the under-dose group compared with the appropriate standard-dose group (adjusted HR, 0.474; 95\% CI, $0.185-1.071 ; \mathrm{P}=0.0739)$. Third, the risk for all-cause death was higher in the appropriate low-dose than in the standarddose group (adjusted HR, 2.805; 95\% CI, 1.306-6.291; $\mathrm{P}=0.0075$ ), with no difference between the appropriate standard-dose and either the under- or over-dose groups. The risk for the composite of net clinical events was higher in the over-dose than in the appropriate standard-dose groups (adjusted HR, 2.714; 95\% CI, 1.313-5.269; $\mathrm{P}=0.0081$ ), with no difference between the appropriate standard-dose and either the under- or over-dose groups.

\section{Discussion}

The major findings of our study were as follows. First, over-dosing DOAC therapy was identified in $4.0 \%$ of our study group, with under-dosing of $22.2 \%$. Patients in the off-label over-dose, under-dose and appropriate lowerdose groups tended to be older and at higher risk for a 


\begin{tabular}{|c|c|c|c|c|c|}
\hline & $\begin{array}{c}\text { Event rate per } 100 \\
\text { patient-years }\end{array}$ & $\begin{array}{c}\text { Crude HR } \\
(95 \% \mathrm{Cl})\end{array}$ & $P$ value & $\begin{array}{c}\text { *Adjusted HR } \\
(95 \% \mathrm{Cl})\end{array}$ & $P$ value \\
\hline \multicolumn{6}{|l|}{ Stroke/SE } \\
\hline Appropriate standard-dose & 1.17 & Ref. & & Ref. & \\
\hline Under-dose & 1.02 & $0.879(0.415-1.741)$ & 0.7182 & $0.851(0.391-1.746)$ & 0.6675 \\
\hline Appropriate low-dose & 2.06 & $1.819(1.053-3.154)$ & 0.0321 & $1.163(0.388-1.894)$ & 0.7090 \\
\hline Over-dose & 3.53 & $3.099(1.151-7.075)$ & 0.0275 & $2.249(0.694-6.117)$ & 0.1650 \\
\hline \multicolumn{6}{|l|}{ Major bleeding } \\
\hline Appropriate standard-dose & 1.21 & Ref. & & Ref. & \\
\hline Under-dose & 0.64 & $0.524(0.210-1.143)$ & 0.1079 & $0.474(0.185-1.071)$ & 0.0739 \\
\hline Appropriate low-dose & 1.45 & $1.195(0.652-2.149)$ & 0.5575 & $1.231(0.522-2.901)$ & 0.6353 \\
\hline Over-dose & 3.00 & $2.523(0.853-6.040)$ & 0.0885 & $2.367(0.695-6.555)$ & 0.1554 \\
\hline \multicolumn{6}{|l|}{ Death } \\
\hline Appropriate standard-dose & 0.64 & Ref. & & Ref. & \\
\hline Under-dose & 1.29 & $1.967(0.929-4.161)$ & 0.0763 & $1.782(0.810-3.925)$ & 0.1493 \\
\hline Appropriate low-dose & 4.07 & $6.404(3.661-11.99)$ & $<0.0001$ & $2.805(1.306-6.291)$ & 0.0075 \\
\hline Over-dose & 4.01 & $6.205(2.351-14.92)$ & 0.0006 & $2.230(0.591-7.155)$ & 0.2239 \\
\hline \multicolumn{6}{|l|}{ Composite net clinical events } \\
\hline Appropriate standard-dose & 2.31 & Ref. & & Ref. & \\
\hline Under-dose & 2.61 & $1.121(0.696-1.770)$ & 0.6316 & $1.058(0.643-1.710)$ & 0.8220 \\
\hline Appropriate low-dose & 6.17 & $2.699(1.899-3.877)$ & $<0.0001$ & $1.482(0.894-2.477)$ & 0.1276 \\
\hline Over-dose & 10.49 & $4.577(2.561-7.784)$ & $<0.0001$ & $2.714(1.313-5.269)$ & 0.0081 \\
\hline
\end{tabular}

*Adjusted by propensity score calculated using sex, age, body weight, persistent $A F$, new use, hypertension, diabetes mellitus, heart failure, history of stroke/TIA, vascular disease, history of AF ablation, creatinine clearance, antiplatelet drug use. $\mathrm{Cl}$, confidence interval; HR, hazard ratio. Other abbreviations as in Tables 1,2 .

stroke than those in the appropriate standard-dose group. After multivariate adjustment, the risk for stroke/SE, death and the composite of net clinical events was equivalent between the appropriate standard-dose and the under-dose groups. However, the risk for a major bleeding event tended to be lower in the under-dose than in the appropriate standard-dose group. The composite of net clinical events in the over-dose group was higher than in the standarddose group. The incidence rate of stroke/SE, major bleeding event and composite event was equivalent between the appropriate low- and standard-dose groups, although the mortality rate was higher in the appropriate low- than standard-dose group.

\section{Prevalence and Baseline Patients' Characteristics of Off-Label DOAC Therapy}

Of the overall rate of off-label under-dosing of $22.2 \%$, the distribution among the 4 DOACs used was as follows: dabigatran, 20.0\%; rivaroxaban, $24.7 \%$; apixaban, $19.7 \%$; and edoxaban, $27.6 \%$. The distribution of cases of overdosing was as follows: dabigatran, $7.7 \%$; rivaroxaban, 3.4\%; apixaban, $0.7 \%$; and edoxaban, 6.7\%. Previous real-world data from the ORBIT-AF2 registry revealed an incidence rate of under-dosing of DOAC therapy of only $9.4 \%$ (compared with our rate of $22.2 \%$ ), with a rate of $3.4 \%$ of over-dosing. ${ }^{14}$ In a real-world registry in Europe, the rate of inappropriate under-dose DOAC therapy was $18 \% .{ }^{15}$ In contrast, in Japan the Fushimi AF registry reported a rate of under-dosing of $29 \%$ for dabigatran, $21 \%$ for rivaroxaban and $26 \%$ for apixaban. ${ }^{7}$ It is possible that the higher rates of under-dosing of DOACs in Japan, compared with other real life registries, reflect the higher risk for major bleeding with warfarin anticoagulant therapy in Asians, compared with non-Asians. ${ }^{16-21}$ As we previously reported, patients in the under-dose group were older than those in the appropriate standard-dose group, with no history of alcohol abuse and only moderate renal impairment. Age $>75$ years and impaired renal function are known risk factors for stroke and bleeding. ${ }^{22,23}$ It is, therefore, not surprising that physicians would favor under-dosing for older Asian patients with some renal dysfunction in order to lower the risk of a major bleeding event. The RELY and Engage AF trials reported on the effectiveness of low-dose dabigatran and edoxaban therapy. ${ }^{2,5}$ By contrast, the ROCKET AF and ARISTOTLE trials were under-powered, with too few patients in the low-dose DOAC group to establish superiority, equivalence or non-inferiority of under-dosing, compared with appropriate standard dose.,4 Based on current evidence, underdosing of dabigatran and edoxaban is a possible option for DOAC therapy to lower the risk of bleeding in Japanese patients with AF.

With regard to over-dosing of DOACs, patients in this group were older, more likely to be female, were prescribed dabigatran more often, had a higher $\mathrm{CHA}_{2} \mathrm{DS}_{2}-\mathrm{VASc}$ score, and lower renal function than patients in the appropriate standard-dose group. These findings are consistent with those of a previous study, using real-world data in the USA, reporting that patients who were receiving overdosing of DOACs were older, more likely to be women and had a higher $\mathrm{CHA}_{2} \mathrm{DS}_{2}$-VASc score. ${ }^{14}$ It is possible that the over-dosing in these patients is not "intended", but rather occurs over time with a decrease in body weight and/or serum creatinine concentration, which might be overlooked in clinical practice. 


\section{Clinical Outcomes Among the 4 DOAC Dose Groups}

Patients in the off-label under-dose DOAC group were significantly older and had a higher risk of stroke than patients in the appropriate standard-dose group. Based on patients' characteristics, we hypothesized that the stroke/ SE rates would be higher in the under-dose than in the appropriate standard-dose group. However, the incidence rate of stroke/SE was comparable between these groups, with lower dosing of DOACs reducing the incidence rate of major bleeding compared with the appropriate standarddose group. Prior to our study, there were only a few reports on the outcomes of off-label under-dose DOAC users in Japan. A single-center, retrospective study reported inappropriate low-dosing, especially when unintended (related to increased body weight or decreased serum creatinine concentration), to be a risk factor for recurrent ischemic stroke. ${ }^{24}$ In agreement with our results, another study did not find under-dosing of DOACs to be associated with more severe stroke or poorer clinical outcomes, compared with the recommended dose. ${ }^{25}$ These 2 Japanese studies, however, had small sample groups. Therefore, from a statistical standpoint, we deem that our registry data provided a more accurate representation of patients with AF in the clinical settings in Japan.

Our findings, however, do differ from those reported in 2 previously reported large-scale RCTs of DOAC therapy, namely, the RE-LY and ENGAGE AF TIMI-48 studies, ${ }^{2,5,11}$ and a previously reported observational study. ${ }^{14}$ Both of the $\mathrm{RCT}$ s reported a higher stroke/SE rate but a lower rate of major bleeding events, in the low-dose compared with standard-dose DOAC groups, when patient characteristics were controlled for. ${ }^{2,5,11,21}$ Analysis of the data in the ORBIT-AF2 registry in the USA did not reveal a statistical association between under-dosing of DOAC therapy and an increase in stroke/SE events or a decrease in major bleeding events, although the mortality rate tended to be higher among patients treated with an under-dose compared with a standard-dose. ${ }^{14}$ Several possible explanations could account for observed differences between our results and those of the previous studies. Foremost, we must consider differences in the patients' background characteristics. Specifically, the previous studies drew their study samples from Western countries, with the average body weight of $80 \mathrm{~kg}$ being greater than the average body weight of our study sample. Body weight is an important factor to consider, as the risk of stroke/SE and bleeding during DOAC therapy is related to the dose of DOAC relative to a patient's body weight. The dose regimen of DOACs in Japan is the same as that used in the RCTs, and generally reported in other countries, with the exception of rivaroxaban, for which the standard dose is $15 \mathrm{mg}$ and the reduced dose $10 \mathrm{mg}$, based on known pharmacokinetics of rivaroxaban in Japanese adults. ${ }^{\mathbf{2 6}}$ Therefore, the reduced dose might be sufficient for the prevention of stroke/SE among Japanese patients who have a relatively lower body weight compared with Europeans and other Westerners. The nationwide coverage of health benefits by public health insurance in Japan may also be an important factor to consider because this universal coverage would increase the availability (and use) of hypertensive and/or lipid-lowering drugs. ${ }^{27}$ In fact, the composite of net clinical events has been reported to be lower among Japanese patients with $\mathrm{AF}^{6,7,9}$ than among patients enrolled in the 2 previously published RCTs R,5,11 $^{2}$ and the observational study in the USA. ${ }^{14}$ Certainly, the lower burden of vascular disease and bleeding and the longevity of Japanese individuals compared with Europeans and other Westerners must be considered. However, the lower incidence rate of the composite of net clinical events in the under-dose DOAC group may be partially mediated by antiplatelet therapy, with these drugs lowering the risk of stroke and the occurrence of any hemorrhagic events. In fact, in an RCT and an observational study, anticoagulant therapy was shown to lower the risk of stroke $\mathrm{k}^{4}$ or increase the risk of bleeding. 7,11,19 In our study sample, the use of antiplatelet therapy was equivalent between the under-dose and appropriate standard-dose groups, with no association observed between antiplatelet therapy and clinical adverse events in the under-dose group. Therefore, under-dosing of DOACs may not increase the risk of stroke but does reduce the risk of bleeding among Japanese patients with AF. As such, under-dosing provides a safe treatment for Japanese patients who are at greater risk for bleeding associated with anticoagulant therapy. It is important to note, however, that prescription of a standard-dose to patients in the under-dose group could lead to an increased incidence of a bleeding event, but decreased risk of a stroke. Evaluation of this possibility is difficult because patients in the standarddose group in the SAKURA AF Registry were younger than those in the under-dose group. As such, the risk for stroke/SE would naturally be lower in the standard- than in the under-dose group.

Off-label over-dosing of DOACs was independently associated with an increased incidence rate of net clinical events, with the appropriate low-dose being independently associated with an increase in all-cause death events compared with appropriate standard-dose users. Compared with the standard-dose group, the off-label over-dose and appropriate low-dose groups had a higher proportion of women, with patients being older, having a lower body weight and higher risk score for stroke and bleeding. These patient characteristics are well known to be strong risks for adverse clinical events, and more specifically, death. ${ }^{2-7,9}$ The effects of these factors may not have been completely controlled for in our analysis, even after multivariate adjustment. Therefore, the association between off-label DOAC over-dose or appropriate low-dose and a higher incidence rate of the composite net clinical events and death might reflect this inherent patient bias, rather than the specific dose used. Nonetheless, as over-dosing of DOACs is related to poor outcomes, including an increased incidence rate of stroke/SE, major bleeding event and all-cause death, ${ }^{14}$ as per our findings, patients on an overdose of DOAC should be carefully and intensively followed up, and physicians should consider all risk factors prior to intentionally prescribing over-dosing of a DOAC.

\section{Study Limitations}

The present study has several limitations that should be acknowledged. First is the unavoidable possibility of a selection bias because of being a prospective observational study, despite our use of Cox proportional hazards models to minimize the influence of patients' background factors. As previously described, there is a likelihood of multiple residual confounders, which were not fully adjusted for in the multivariate models and may have biased our results. Second, the registry included patients only from selected institutions located in the capital city of Tokyo, or its suburbs. Therefore, the data, and our findings, may not be reflective of all areas of Japan. We note, however, that 
patient selection and regional enrollment biases are limitations of all prospective observational studies. Third, patients using p-glycoprotein inhibitors would have been considered as under-dosing candidates. However, this information is not specifically available in the SAKURA AF Registry and therefore could not be accounted for in our results. Fourth, the dose of rivaroxaban used in Japan differs from that used in other countries, with $15 \mathrm{mg}$ being the standard dose in Japan, $20 \mathrm{mg}$ being used as a high dose and $10 \mathrm{mg}$ as a low dose. Therefore, clinical outcomes between the 4 different dose groups for rivaroxaban are specific to Japan. Nonetheless, our data on the effectiveness and safety of the Japan-specific dose may provide clinical insight into understanding AF treatment in some Western and Asian patients who have a body type similar to that of Japanese people. Fifth, we defined 'off-label low-dosing' of DOACs using the criteria for a low-dose regimen. As such, off-label low-dosing for dabigatran and edoxaban will be different than the off-label low-dosing for rivaroxaban and apixaban, with the effectiveness and safety of low doses of dabigatran and edoxaban having been well-established, even in patients on low-dose regimens in clinical trials. ${ }^{\mathbf{2}, 5}$ Finally, our evaluation of the effects of the 4 different doses of DOACs should be considered with caution because of the relatively overall low rate of clinical events. Therefore, future studies are needed to evaluate dose-associated effects for the 4 DOACs on the rate of clinical adverse events.

\section{Conclusions}

Although patients administered off-label under-dose DOAC therapy were older and at a higher risk of stroke than patients in the appropriate standard-dose group, the rate of stroke was equivalent between the 2 groups, while the rate of major bleeding events tended to be lower in the under- than in the standard-dose group. Further studies are needed to clarify the safety and effectiveness of off-label under-dose DOAC therapy in Japanese patients. Over-dose DOAC users were at a significantly higher risk for all clinical events, with appropriate low-dose users being at significantly higher risk of death, than standard-dose users, requiring careful follow-up of these patients.

\section{Acknowledgments}

The authors thank all the centers that participated in the study and all the patients who consented to participate.

\section{Disclosures}

Y. Okumura accepted remuneration from Daiichi-Sankyo; A. Hirayama received research funding from Bayer Healthcare, Daiichi-Sankyo, Otsuka Pharmaceutical, Astellas Pharma, Eisai, Sumitomo Dainippon Pharma, MSD, Nihon Medi-Physics, Bristol-Meyers Squibb, Boehringer Ingelheim, Pfizer, Boston Scientific Corporation, and Hokushin Medical, and has accepted remuneration from Bayer Healthcare, Daiichi-Sankyo, Eisai, Bristol-Meyers Squibb, Astellas Pharma, Sanofi, and Takeda Pharmaceutical; N. Matsumoto received research funding from Daiichi-Sankyo, Otsuka Pharmaceutical, and Sumitomo Dainippon Pharma, and accepted remuneration from Nihon Medi-Physics, FUJIFILM RI Pharma, and Biosensors Interventional Technologies Japan.

\section{Funding Sources}

The study was financially supported by Bayer Yakuhin Ltd., and conducted as an investigator-initiated research based on the contract with Bayer Yakuhin Ltd. The study was also supported by scholarship funds from Daiichi-Sankyo, Astellas Pharma, Eisai, Sumitomo
Dainippon Pharma, MSD, Nihon Medi-Physics, Bristol-Meyers Squibb, Boehringer Ingelheim, and Pfizer.

\section{References}

1. Inoue H, Fujiki A, Origasa H, Ogawa S, Okumura K, Kubota I, et al. Prevalence of atrial fibrillation in the general population of Japan: An analysis based on periodic health examination. Int $J$ Cardiol 2009; 137: 102-107.

2. Connolly SJ, Ezekowitz MD, Yusuf S, Eikelboom J, Oldgren J, Parekh A, et al; RE-LY Steering Committee and Investigators. Dabigatran versus warfarin in patients with atrial fibrillation. $N$ Engl J Med 2009; 361: 1139-1151.

3. Patel MR, Mahaffey KW, Garg J, Pan G, Singer DE, Hacke W, et al; ROCKET AF Investigators. In Comment regarding: Rivaroxaban versus warfarin in nonvalvular atrial fibrillation. $N$ Engl J Med 2011; 365: 883-891.

4. Granger CB, Alexander JH, McMurray JJ, Lopes RD, Hylek EM, Hanna M, et al; ARISTOTLE Committees and Investigators. Apixaban versus warfarin in patients with atrial fibrillation. $N$ Engl J Med 2011; 365: 981-992.

5. Giugliano RP, Ruff CT, Braunwald E, Murphy SA, Wiviott $\mathrm{SD}$, Halperin JL, et al; ENGAGE AF-TIMI 48 Investigators. Edoxaban versus warfarin in patients with atrial fibrillation. $N$ Engl J Med 2013; 369: 2093-2104.

6. Kodani E, Atarashi H, Inoue H, Okumura K, Yamashita T, Origasa H; J-RHYTHM Registry Investigators. Beneficial effect of non-vitamin $\mathrm{K}$ antagonist oral anticoagulants in patients with non valvular atrial fibrillation: Results of the J-RHYTHM Registry 2. Circ J 2016; 80: 843-851.

7. Yamashita Y, Uozumi R, Hamatani Y, Esato M, Chun YH, Tsuji H, et al. Current status and outcomes of direct oral anticoagulant use in real-world atrial fibrillation patients: Fushimi AF Registry. Circ J 2017; 81: 1278-1285.

8. Okumura Y, Yokoyama K, Matsumoto N, Tachibana E, Kuronuma K, Oiwa K, et al. Current use of direct oral anticoagulants for atrial fibrillation in Japan: Findings from the SAKURA AF Registry. J Arrhythmia 2017; 33: 289-296.

9. Okumura Y, Yokoyama K, Matsumoto N, Tachibana E, Kuronuma K, Oiwa K, et al; SAKURA AF Registry Investigators. Three-year clinical outcomes associated with warfarin vs. direct oral anticoagulant use among Japanese patients with atrial fibrillation: Findings from the SAKURA AF Registry. Circ J 2018; 82: $2500-2509$.

10. Rosendaal FR, Cannegieter SC, van der Meer FJ, Briët E. A method to determine the optimal intensity of oral anticoagulant therapy. Thromb Haemost 1993; 69: 236-239.

11. Eikelboom JW, Wallentin L, Connolly SJ, Ezekowitz M, Healey JS, Oldgren J, et al. Risk of bleeding with 2 doses of Dabigatran compared with warfarin in older and younger patients with atrial fibrillation: An analysis of the randomized evaluation of long-term anticoagulant therapy (RE-LY) trial. Circulation 2011; 123: $2363-2372$.

12. Hori M, Matsumoto M, Tanahashi N, Momomura S, Uchiyama $\mathrm{S}$, Goto $\mathrm{S}$, et al. J-ROCKET AF study investigators. Rivaroxaban vs. warfarin in Japanese patients with atrial fibrillation: The J-ROCKET AF study. Circ J 2012; 76: 2104-2111.

13. Ogawa S, Shinohara Y, Kanmuri K. Safety and efficacy of the oral direct factor Xa inhibitor apixaban in Japanese patients with non-valvular atrial fibrillation: The ARISTOTLE-J study. Circ $J$ 2011; 75: 1852-1859.

14. Steinberg BA, Shrader P, Thomas L, Ansell J, Fonarow GC, Gersh BJ, et al. Off-label dosing of non-vitamin K antagonist oral anticoagulants and adverse outcomes: The ORBIT-AF II Registry. J Am Coll Cardiol 2016; 68: 2597-2604.

15. Ruiz Ortiz M, Muñiz J, Raña Míguez P, Roldán I, Marín F, Esteve-Pastor MA, et al. Inappropriate doses of direct oral anticoagulants in real-world clinical practice: Prevalence and associated factors. A subanalysis of the FANTASIIA Registry. Europace 2018; 20: 1577-1583.

16. Shen AY, Yao JF, Brar SS, Jorgensen MB, Chen W. Racial/ ethnic differences in the risk of intracranial hemorrhage among patients with atrial fibrillation. J Am Coll Cardiol 2007; 50: 309-315.

17. van Asch CJ, Luitse MJ, Rinkel GJ, van der Tweel I, Algra A, Klijn CJ. Incidence, case fatality, and functional outcome of intracerebral haemorrhage over time, according to age, sex, and ethnic origin: A systematic review and meta-analysis. Lancet Neurol 2010; 9: 167-176.

18. Hori M, Connolly SJ, Zhu J, Liu LS, Lau CP, Pais P, et al. 
Dabigatran versus warfarin: Effects on ischemic and hemorrhagic strokes and bleeding in Asians and non-Asians with atrial fibrillation. Stroke 2013; 44: 1891-1896.

19. Hori M, Matsumoto M, Tanahashi N, Momomura SI, Uchiyama S, Goto S, et al. Predictive factors for bleeding during treatment with rivaroxaban and warfarin in Japanese patients with atrial fibrillation: Subgroup analysis of J-ROCKET AF. $J$ Cardiol 2016; 68: 523-528.

20. Goto S, Zhu J, Liu L, Oh BH, Wojdyla DM, Aylward P. Efficacy and safety of apixaban compared with warfarin for stroke prevention in patients with atrial fibrillation from East Asia: A subanalysis of the Apixaban for reduction in stroke and other thromboembolic events in atrial fibrillation (ARISTOTLE) trial. Am Heart J 2014; 168: 303-309.

21. Yamashita T, Koretsune Y, Yang Y, Chen SA, Chung N, Shimada YJ. Edoxaban vs. warfarin in East Asian patients with atrial fibrillation: An ENGAGE AF-TIMI 48 subanalysis. Circ $J$ 2016; 80: 860-869.

22. Gage BF, Waterman AD, Shannon W, Boechler M, Rich MW, Radford MJ. Validation of clinical classification schemes for predicting stroke: Results from the National Registry of Atrial Fibrillation. JAMA 2001; 285: 2864-2870.

23. Pisters R, Lane DA, Nieuwlaat R, de Vos CB, Crijns HJ, Lip GY. A novel user-friendly score (HAS-BLED) to assess 1-year risk of major bleeding in atrial fibrillation patients: The Euro Heart Survey. Chest 2010; 138: 1093-1100.

24. Shinoda N, Mori M, Tamura S, Korosue K, Kose S, Kohmura E. Risk of Recurrent ischemic stroke with unintended low-dose oral anticoagulant therapy and optimal timing of review. $J$ Stroke Cerebrovasc Dis 2018; 27: 1546-1551.

25. Kato Y, Hayashi T, Tanahashi N, Takao M. The dose of direct oral anticoagulants and stroke severity in patients with acute ischemic stroke and non-valvular atrial fibrillation. J Stroke Cerebrovasc Dis 2018; 27: 1490-1496.

26. Tanigawa T, Kaneko M, Hashizume K, Kajikawa M, Ueda H, Tajiri M, et al. Model-based dose selection for phase III Rivaroxaban study in Japanese patients with non-valvular atrial fibrillation. Drug Metab Pharmacokinet 2013; 28: 59-70.

27. Bhatt DL, Eagle KA, Ohman EM, Hirsch AT, Goto S, Mahoney EM, et al. Comparative determinants of 4-year cardiovascular event rates in stable outpatients at risk of or with artherothrombosis. JAMA 2010; 304: 1350-1357.

\section{Supplementary Files}

Please find supplementary file(s); http://dx.doi.org/10.1253/circj.CJ-18-0991 